\title{
Conjecturas psicanalíticas acerca da Desordem de Personalidades Múltiplas
}

\author{
Psychoanalytical conjectures about Multiple Personality Disorder
}

Allan Martins Mohr ${ }^{[0]}$, Fabio Thád ${ }^{[b]}$

\footnotetext{
${ }^{[a]}$ Graduado em Psicologia pela Universidade Federal do Paraná, Mestrando em Psicologia pela Universidade Federal do Paraná (UFPR), psicólogo (técnicoadministrativo) da Universidade Tecnológica Federal do Paraná, Especialista em Psicanálise: Teoria e Prática pela Faculdade Dom Bosco, Curitiba, PR - Brasil, e-mail: allan.mohr@gmail.com

${ }^{[b]}$ Psicólogo, psicanalista, Doutor em Estudos Linguísticos, professor da Faculdade Dom Bosco, Curitiba, PR - Brasil.
}

Recebido: 03/03/2010 Received: 03/03/2010

Aprovado: 19/05/2010 Approved: 05/19/2010

\section{Resumo}

Na literatura mundial, tornou-se comum a existência de heróis e anti-heróis com uma característica peculiar: a dupla personalidade. Entretanto, diferentemente do que se sabe acerca dessa divisão moral da personalidade, divisão caracterizada por uma personalidade "do bem" e outra "do mal", os casos de Transtorno Dissociativo de Identidade, ou Desordem de Personalidades Múltiplas (DPM), são bem mais complexos e apresentam uma estrutura e um mecanismo peculiarmente desenvolvidos. Neste artigo, tal entidade clínica é estudada sob a luz da psicanálise, com o intuito de elaborar conjecturas que deem conta de explicar sua etiologia e seu mecanismo de funcionamento. Dois casos históricos, Sybil Dorsett, uma jovem com 13 personalidades, e Karen Overhill, com 17 alteregos, relatados respectivamente por Schreiber (1983) e Baer (2007), são confrontados com a teoria freudiana, e uma hipótese sobre a estruturação do mundo mental nessa patologia é formulada. Críticas sobre a existência da referida desordem enquanto entidade clínica verdadeira são rebatidas e, finalmente, é apresentada uma leitura a respeito do que acreditamos ser uma possibilidade de explicação para o fenômeno, explicação esta que lança questões sobre a teoria das estruturas psíquicas em psicanálise e abre campo para a possibilidade de se cogitar uma nova estrutura possível para o ser humano.

Palavras-chave: Psicanálise. Constituição do sujeito. Personalidade.

\section{Abstract}

The existence of heroes and anti-heroes with a peculiar characteristic, known as double personality, has become common in literature worldwide. However, differently from what it is known about this moral division of personality, which is characterized by both a "good personality" and an "evil personality", the cases of Dissociative Personality Disorder or Multiple Personality Disorder (MPD) are much more complex and present structure and mechanism peculiarly developed. Such clinical entity is studied under the light of psychoanalysis in this article, with the objective of developing conjectures which can provide explanations about its etiology and also its working mechanism. Two historical cases: Sybil Dorsett, a girl with 13 personalities, and Karen 
Overhill, with 17 alter-egos, reported by Schreiber (1983) and Baer (2007), respectively, are confronted against the Freudian theory, and a hypothesis is formulated on a framework of the mental world in this pathology. Critics about the existence of the so-called disorder as a real clinical entity are discussed and, at last, an explanation for the phenomenon is presented. That explanation casts questions onto the theory of mental structures in psychoanalysis and gives place to the possibility of considering a new possible structure for the human being.

Keywords: Psychoanalysis. Constitution of the subject. Personality.

A literatura mundial está repleta de personagens que estampam um mesmo dilema, uma visão separatista entre uma personalidade "do bem" e outra personalidade "do mal". É o caso de Dr. Jekkyl e Mr. Hyde, em que este era a personificação da raiva e da hostilidade que Jekkyl não podia sentir nem expressar. 0 herói He-Man era a personificação da coragem que sua outra personalidade, o príncipe Adam, não possuía. E, além deles, Hulk e o inimigo do Batman, o sempre indeciso Duas-Caras, são bons exemplos da mesma questão.

Diferentemente dessa posição que preconiza a cisão entre uma personagem boa e outra personalidade má, Sybil e Karen são sujeitos de dois relatos históricos acerca do que a Psiquiatria moderna convencionou chamar de Transtorno de Personalidades Múltiplas (DPM), conforme considerado pela American Psychiatric Association (2002) - entidade clínica específica, que anteriormente era denominada Desordem de Personalidades Múltiplas (denominação que utilizaremos ao longo deste artigo, a fim de tentarmos nos desvencilhar da visão psiquiátrica atual).

Historicamente, o estudo da personalidade múltipla vem sendo afastado dos círculos das teorias psicológicas em função de críticas - diga-se de passagem, consistentes - relacionadas a esses casos, e sendo restringido à Psiquiatria.

Duas dessas críticas são como a seguir: a primeira, relacionada à hipótese de que essa doença é cultural, sendo apresentada, se não única, então substancialmente inserida na sociedade americana; e a segunda, relacionada à conjectura de que a fenomenologia apresentada, ou seja, a existência de mais de uma personalidade no sujeito humano, não passaria de uma teatralidade histérica.

As críticas e o consequente afastamento da referida entidade clínica das discussões acadêmicas e científicas, em nosso entendimento, faz-se perder a incrível relevância que este estudo apresenta no entendimento a respeito do aparelho psíquico e o problema mente-corpo.

É no intuito de estudar a etiologia e o mecanismo de funcionamento da DPM à luz da psicanálise, que propomos, neste artigo, revisar os casos de Sybil Dorsett, relatado por Flora Rheta Schreiber (1983), e o de Karen Overhill, relatado por Richard Baer (2007), com o propósito de embasar clinicamente nossas conjecturas.

O livro Sybil, escrito por Schreiber, pode ser considerado um dos clássicos da Psiquiatria quando se trata de casos de múltiplas personalidades.

A autora, Flora Rheta Schreiber, na época da primeira edição do livro (lançado em maio de 1973), era especialista em Educação, professora do University of New York's John College of Criminal Justice e havia sido editora de Psiquiatria do Science Digest, além de ser "autora de artigos sobre assuntos psiquiátricos" (Schreiber, 1983, p. 13). Sua profissão e atuação como escritora provavelmente foi o que aproximou Flora da Dra. Cornelia B. Wilbur, psiquiatra e psicanalista, que analisou Sybil entre os anos de 1954 e 1965, percorrendo um total de "2.354 sessões no consultório” (Schreiber, 1983, p. 15).

Flora foi apresentada a Sybil no "outono de 1962, num restaurante da Madison Avenue, em Nova York" (Schreiber, 1983, p. 13), e, a partir de então, trava-se uma amizade que, dez anos ulteriormente, proporciona à sociedade um livro/relato de um dos casos mais conhecidos de múltiplas personalidades.

"O tratamento começou no dia 10 de agosto e continuou uma vez por semana durante todo o verão e começo do outono de 1945" (Schreiber, 1983, p. 46). Sybil havia sido mandada do colégio onde estudava, na cidade de Omaha, para casa e havia sido advertida de que só deveria retornar às aulas quando estivesse melhor. "Miss Updike, a enfermeira 
da escola, estava preocupada comigo" (Schreiber, 1983, p. 43), disse Sybil à Dra. Wilbur em seu primeiro atendimento. A paciente

desandou com uma enxurrada de queixas contra o que estava acontecendo com a sua saúde: a sua falta de apetite, seu peso de uns quarenta quilos, embora tivesse uma altura considerável. Todo este rosário de lamúrias não excluiu a sinusite crônica e a vista curta, tão curta que, conforme adiantou, "às vezes tenho a impressão de estar olhando por meio de um túnel" (Schreiber, 1983, p. 44).

Mas o que a paciente não havia contado era que além desses sintomas físicos, outros a atormentavam mais do que tudo. Como explora Flora, Sybil "logo tranquilizou-se, porque achava que não devia ter dito aquilo que não podia ser dito" e "percebeu conscientemente que nunca conseguiria dizer à Dra. Wilbur tudo o que deveria e poderia, a respeito de sua pessoa" (Schreiber, 1983, p. 45).

Foi somente depois de algum tempo e de muito lutar contra a vontade de seu pai e de sua mãe para iniciar um tratamento, que, em outubro de 1954, depois de nove anos da primeira consulta (estivera em tratamento até outubro de 1945) e já independente financeiramente, resolveu se transferir para Nova York, onde a Dra. Wilbur trabalhava na época, como analista formada.

0 que Sybil não conseguiu explicar inicialmente à Dra. Wilbur foi que "coisas estranhas e incompreensíveis lhe haviam acontecido" e que "estas coisas não eram novidade e na realidade lhe aconteciam desde a idade de 3 anos e meio, e começaram a afetar a sua consciência e entendimento aos 14 anos" (Schreiber, 1983, p. 59-60). Além disso, não conseguiu contar que

pessoas que ela nunca havia visto afirmavam insistentemente que já a conheciam. Seria capaz de ir a um piquenique e sentir uma vaga impressão de ter estado no mesmo local, anteriormente. Um vestido que nunca havia comprado podia muito bem estar dependurado no seu armário. Seria capaz de começar a pintar um quadro e voltar ao estúdio e achar que outra pessoa o havia completado - num estilo que não era o dela. [...] Muitas eram as ocasiões em que tinha a impressão de ter acordado sem ter ido dormir, de ter ido dormir para então acordar, não na manhã seguinte, mas numa data qualquer que não conseguia reconhecer (Schreiber, 1983, p. 60).
Tudo isso que não foi expresso em palavras, Sybil realizou num ato particularmente interessante. Em 21 de dezembro de 1954, Sybil pergunta à Dra. Wilbur se esta gostaria de ver uma carta que a paciente então recebera de Stan, um amigo que propusera casamento a ela, porém, o objetivo não era preenchido por amor.

Quando buscara a carta em sua bolsa, Sybil se apercebeu que havia ali apenas metade da carta. 0 mais intrigante é que "ela não havia rasgado a carta" (Schreiber, 1983, p. 68). Quando a Dra. Wilbur questionou se Sybil gostaria que ela lesse a carta, aquela mulher (a paciente, mas que naquele momento já não era Sybil) pôs-se de pé esbravejando e movimentando-se como nunca havia feito, para em seguida, com os punhos, quebrar a janela do consultório. "Essa coisa acontecera de novo" (Schreiber, 1983, p. 68).

Visando a clarificar os fenômenos aqui relatados, cabe discorrermos acerca da biografia de Sybil Isabel Dorsett. Ela nasceu no ano de 1923, na cidade de Willow Corners. Seus pais, Willard e Hattie Dorsett, na ocasião, contavam 40 anos de idade. Os habitantes da cidade de Willow Corners, na visão de Vicky, uma das personalidades de Sybil, eram "tacanhos, provincianos e obscuros” (Schreiber, 1983, p. 171), puritanos e religiosos.

0 pai de Sybil era atencioso, mas não se preocupava muito, nem com as coisas, nem com Sybil. Um homem dominado pela mulher, um homem sem voz. A mãe, controladora ao extremo. Por mais de uma vez e por diferentes psiquiatras, Hattie Dorsett fora diagnosticada como esquizofrênica, demonstrando, entre seus sintomas, desde catatonia até momentos de euforia delirante.

De 1923 até 1932, quando contava com 9 anos de idade, Sybil dormia num berço no quarto dos pais e presenciava quase toda noite a parte obscura de uma contradição gritante. De dia, uma família recatada que aos olhos dos outros vivia sobre a mais rija lei religiosa; de noite, se permitia a todos os comportamentos sexuais perante o berço de sua única filha.

No caso de Sybil a cena primal não consistia numa olhada de relance e momentânea, não era nenhum momento acidental. Era coisa de todo momento, algo que sempre estava presente. Durante nove anos Sybil fora testemunha dos atos sexuais de seus pais como se fossem uma parte fixa e imutável de sua vida, e em notável contraste com a excessiva reserva e frieza do comportamento deles durante o dia. 
Em público, seu pai e sua mãe nunca se beijavam, nunca se tocavam [...]. A observação da cópula dos pais se deu, contudo, numa casa em que o sexo era encarado como uma perversão... (Schreiber, 1983, p. 194).

Além de conviver com uma contradição que, ao passar dos anos, foi ficando cada vez mais incompreensível, Sybil ainda tinha que lidar com outros fatos perturbadores: "por exemplo, havia as célebres escapadelas noturnas de Hattie" (Schreiber, 1983 , p. 214).

Desde antes da idade de 3 anos, Sybil observava, nas andanças noturnas com sua mãe, um ritual que consistia, por parte de Hattie, em descer as ceroulas e defecar em algum lugar escolhido, "transformando a sua expressão mais corriqueira 'estou cagando para vocês todos' num fato concreto" (p. 215). Além disso, aos domingos, quando os pais iam à Igreja, Hattie Dorsett servia de ama-seca às crianças e brincava de cavalinho com elas; porém, "enquanto ia gritando 'upa-upa', seus dedos funcionavam nas vaginas das garotinhas" (Schreiber, 1983, p. 216).

(...) uma tarde [...] Peggy Lou, ${ }^{1}$ espiando para dentro do quarto de dormir de Willard e Hattie, viu a mãe de Sybil completamente nua, em cima da cama, com uma criancinha entre as pernas. A mãe de Sybil levantava a criança para cima e para baixo com os quadris e esfregava-a no meio das coxas (Schreiber, 1983, p. 216).

Além dessas lembranças, “a análise revelou a existência de um drama de crueldades, rituais secretos, castigos e atrocidades infligidos por Hattie em Sybil" (Schreiber, 1983, p. 217). Entre eles estavam: abrir as pernas da criança com uma colher de pau e, amarrando-as em um fio de luz que pendia do teto, deixava a criança balançando no ar enquanto introduzia um clister para adultos cheio de água na uretra ou vagina da criança e depois, gritando, dava uma gargalhada "que nunca terminava" (Schreiber, 1983, p. 220). Após encher a bexiga de Sybil de água, obrigava-a andar pela sala sem derramar o conteúdo. Se Sybil chorasse, sua mãe dizia: "Espere que lhe dou uma surra para ter motivo de chorar" (Schreiber, 1983, p. 220).
Outros rituais eram realizados, muitos dos quais contemplavam introduzir "com força na vagina da criança uma série de objetos que a cabeça fantasiosa da mãe cogitava" (Schreiber, 1983, p. 221), dizendo que a estava preparando, pois os homens iriam fazer o mesmo com ela, quando crescesse.

Todo esse leque de atrocidades fora confirmado em uma entrevista que seu pai dera à Dra. Wilbur; não que ele soubesse exatamente o que acontecia, pois sempre se defendeu dizendo que uma mãe nunca faria mal a sua filha, mas sabia que algo estranho se dava quando estava fora de casa, pois podia constatar os inúmeros machucados que sua filha apresentava. Médicos, por conseguinte, também puderam verificar que algo infligira muito sofrimento à Sybil durante sua infância:

Hattie preparara a filha tão bem que o hímen de Sybil na infância já estava todo cortado, e a sua vagina estava permanentemente com cicatrizes. Esse preparo fora, contudo, tão eficiente que uma ginecologista, ao examinar Sybil aos 20 anos de idade, declarou que ela, provavelmente, nunca poderia ter uma criança graças aos ferimentos internos (Schreiber, 1983, p. 221).

Por outro lado, a avó de Sybil era o único porto seguro no qual ela podia descansar. Por isso, sua mãe sempre lhe tapava a boca para que a avó Dorsett não ouvisse seus gritos e choros do andar de cima de sua casa: "fora a avó e não a mãe quem cuidara de Sybil quando criança" (Schreiber, 1983, p. 143).

Fato interessante é que Hattie, quando estava em seus momentos de mãe, sem praticar os rituais, chamava Sybil de Peggy e foi esse nome que uma de suas outras personalidades utilizou desde seu nascimento.

Todo o quadro clínico de seu caso de personalidade múltipla iniciou quando Sybil contava 3 anos, conforme relato de Vicky:

Mrs. Dorsett nos levou ao St. Mary's Hospital.

"O médico fez o diagnóstico, dizendo que era tonsilite folicular; mas isto não era tudo. Ele não podia compreender por que nós estávamos mal alimentadas [...] Gostamos dos dias que passamos no St. Mary's Hospital. O médico era alto e jovem. [...] O doutor ria, e nós ríamos também. [...]

\footnotetext{
1 Uma das personalidades de Sybil.
} 
Agarramo-nos ao seu pescoço. Olhávamos para a cara dele e perguntávamos: "O senhor gostaria de ter uma garotinha?" [...]

Mas ele não disse aquilo [...]. O avental branco se desvaneceu no nada..." (Schreiber, 1983, p. 337-338).

Nesse dia nascera a própria Vicky e Peggy Louisiana. Aquela, o reduto das memórias de Sybil e a "coanalisadora" que ajudara a Dra. Wilbur durante o tratamento; esta, que posteriormente se redividiu em Peggy Lou e Peggy Ann, era a personificação do medo e da raiva que Sybil não podia sentir.

Durante os 11 anos de análise, a Dra. Wilbur e a própria Sybil se viram diante de 12 outros habitantes da mente e do corpo da paciente: Marjorie, Ruthie, Marcia, Vanessa, Mary, Helen, Clara, Sybil Ann, Mike, Sid, Nancy Lou Ann e a Loura. Segundo Schreiber, "todas eram diferentes uma da outra e de Sybil; cada uma sabia da existência de Sybil e de cada uma das outras personalidades. Sybil, contudo [...], só teve conhecimento das outras depois que a Dra. Wilbur lhe falou a respeito" (Schreiber, 1983, p. 314).

Essas diferenças eram perceptíveis na idade de cada personalidade, como Ruthie, que era apenas uma criança; e até no sexo das personalidades alternantes: Mike e Sid eram garotos e acreditavam piamente possuir um pênis.

A história de Sybil é "preenchida" com diversos lapsos de tempo, momentos em que as outras personalidades tomavam conta do corpo dela e viviam por ela. Foi assim que Sybil perdeu dois anos na escola, depois da morte de sua avó, e, sem saber como, acordou em uma rua na Filadélfia, depois de cinco dias sem lembrar-se do que ocorrera.

Ao longo do livro, é possível entender que uma explicação para a etiologia da personalidade múltipla é a incapacidade de a personalidade atuante dar vazão às emoções que a ela ocorrem; assim, tem a necessidade de formar uma personalidade outra para trabalhar com essa emoção negada. Nas palavras da Dra. Wilbur, "uma vez que a personalidade alternante tenha dado vazão às emoções que em qualquer tempo a provocaram, não há motivo para ela continuar funcionando" (Schreiber, 1983, p. 331).

Numa tentativa de entendimento científico, a Dra. Wilbur levanta a seguinte hipótese: "Sybil em atividade correspondia mais ou menos à mente consciente, e [...] as personalidades alternantes pertenciam ao inconsciente. [...] Atuavam no íntimo de
Sybil, mas também no mundo exterior, onde pareciam dar vazão ao problema particular que estavam guardando" (Schreiber, 1983, p. 127).

Sendo dessa maneira por ela entendido o fenômeno da personalidade múltipla, a Dra. Wilbur acreditava que o tratamento para tal deveria ser uma psicanálise, porém não ortodoxa (Schreiber, 1983, p. 118); e assim procedeu. "Sybil era a primeira personalidade múltipla a ser submetida à Psicanálise" (Schreiber, 1983, p. 117), mas também recebeu grande auxílio de aplicações de Pentotal e da hipnose.

Fora com esses dois últimos recursos que a Dra. Wilbur conseguiu um grande e rápido avanço no fim do tratamento. Com a hipnose, a Dra. Wilbur conseguiu elevar as idades das personalidades à mesma idade de Sybil, pois acreditava que só assim seria possível integrá-las à personalidade atuante.

Também com o auxílio da hipnose, a médica conseguiu apresentar à paciente os seus alters, o que permitiu que cada um, pouco a pouco, fosse se aproximando de Sybil, se integrando e dividindo com ela as lembranças e sentimentos próprios de cada um. "No dia 2 de setembro de 1965, a Dra. Wilbur registrou o seguinte em seus apontamentos diários de análise do caso Dorsett: 'Todas as personalidades se reduziram a uma só'" (Schreiber, 1983, p. 444).

Depois de todo o tratamento realizado, Sybil regozijava-se da nova pessoa que se tornara, afirmava que agora era completa, e fica impressionada com a vida "normal" que estava levando. "Como é fantástico a gente poder esquecer da mesma maneira como os outros o fazem" (Schreiber, 1983, p. 447), e numa carta escrita em 25 de setembro de 1966, Sybil explica o porquê de sua alegria: "É o primeiro ano contínuo de minha vida. É formidável ver como os dias se desdobram em semanas e as semanas em meses, sobre os quais posso relancear os olhos e recordar" (Schreiber, 1983, p. 454).

Em outro relato de um caso clínico de DPM, mais atual que o de Sybil Dorsett, a entidade clínica ora estudada é novamente apresentada, porém, com especificidades que diferem substancialmente do caso anterior.

Switching Time: a doctor's harrowing story of treating a woman with 17 personalities é um dos mais recentes, se não o mais recente, livro sobre um caso de múltiplas personalidades. Sua história é narrada quase que inteiramente pelo psiquiatra que atendeu a jovem americana Karen Overhill. Quase inteiramente, pois o livro é composto por inúmeras cartas escritas por Karen e seus alters, além do prólogo e 
de uma nota, ao fim do texto, redigidos pela própria paciente. Uma vez que o livro ainda é inédito no Brasil, tomamos a liberdade de transcrever as citações, neste artigo, com uma tradução livre.

O Dr. Richard Baer, em 2007, era o diretor médico da Medicare em Illinois, Indiana, Kentucky, e Ohio. Atendia como psiquiatra clínico e serviu como presidente da Sociedade de Psiquiatria de Illinois.

Em 1989, Baer recebeu a paciente Karen Overhill e, como bem definido na contracapa do seu livro, "levou uma sessão para reconhecer que ele tinha uma paciente no limite - mas uma década para conhecer seus 17 eus" (Baer, 2007).

0 tratamento levou 18 anos, proporcionou aos arquivos médicos de Baer 622 páginas de progresso terapêutico, 44 desenhos enviados pelas personalidades (a maioria, diga-se de passagem, desenvolvidos por Jensen), 49 objetos entregues, 12 fitas de áudio, 2 fitas de vídeo, 60 cartões (cartões de Natal, por exemplo) e 5 mil cartas e diários jornalísticos. Além disso, médico e paciente trocaram 275 e-mails.

Em sua primeira entrevista, Baer $(2007$, p. 7) relata o seguinte: "É dia 11 de janeiro de 1989 [...] Ela tem 29 anos [...] Seus olhos dizem Oi, me desculpe, eu desisto".

Karen acordara em algum hospital, sem ter a menor ideia de por que estaria ali, enfaixada e com o peito doendo. Algum tempo depois, soube que havia dado à luz a sua segunda filha, Sara. 0 problema é que ela não se lembrava disso, muito menos de que era casada e já tinha outro filho. "Durante os primeiros dias depois do nascimento de Sara, eu descobri que tinha um filho de dois anos em casa, James [...] Eu o vi numa foto que minha mãe trouxe. Eu imaginei que ela fosse minha mãe" (Baer, 2007, p. 2).

Ainda no hospital, Karen teve lapsos de tempo que não sabia explicar. Acreditou que estava entrando e saindo de coma continuamente. Ela se obrigou a olhar e estudar todas as fotos que conseguia e gradualmente foi se tornando a pessoa que as fotos diziam que ela era.

Somente após três anos de muito sofrimento é que ela resolveu procurar ajuda. Sua queixa era concentrada no estado depressivo que a acometeu depois do nascimento de sua filha. Três anos e meio, contou Karen ao Dr. Richard Baer. E antes disso, nunca havia estado depressiva - também, como poderia? Nem se lembrava que existia!

Nesse tempo, depois de sua cesariana, Karen ganhou em torno de $45 \mathrm{~kg}$ e, além de depressiva, era submissa demais, segundo suas próprias palavras. Ela tentava agradar a todos e não conseguia dizer 'não', especialmente para sua mãe.

"Volta e meia, eu penso em me matar" (Baer, 2007, p. 11). E, além disso, Karen relatou que seu marido a espancava e disse que ela não tinha mais serventia para ele.

A primeira carta que Karen escreve a Baer, datada de 11 de dezembro de 1989, diz o seguinte:

é 1:30 da manhã e eu não consigo dormir. Eu não sei quanto mais eu posso ir dessa maneira. Eu realmente quero morrer. Eu odeio a mim mesma e a minha vida. [...] Eu só estou esperando o momento certo para morrer. Não sei quando nem onde, mas sinto que será logo. Eu estou perdida. Quero dormir para sempre. Por favor, me ajude antes que seja tarde demais (Baer, 2007, p. 14).

Após essa carta, Karen Overhill foi internada para sua própria proteção.

Mas tão desconcertante quanto essa, a carta a seguir parece ser a responsável pelo início verdadeiro de seu tratamento. A certeza de seu diagnóstico veio pelo correio, numa carta postada em 5 de novembro de 1993, que dizia o seguinte:

Meu nome é Claire. Eu tenho 7 anos. Eu moro dentro da Karen. Eu ouço você o tempo todo. Eu quero falar com você, mas não sei como. Eu brinco com James e Sara e eu canto também. Eu não quero morrer. Pode me ajudar a amarrar meus sapatos? Claire (Baer, 2007, p. 91).

Durante sua estada no hospital, quando foi internada a pedido do Dr. Richard Baer, Karen começou a escrever algumas de suas memórias, e a entregou ao seu médico.

Meu pai é nojento [...] Ele só pensa em sexo. [...] Ele abusava de mim constantemente, física e mentalmente. [...] Ele nunca se importou com ninguém além dele mesmo, ele tratava minha mãe como uma empregada e máquina de fazer sexo. [...] Durante toda a minha vida, dos 5 aos 16 anos, eu era espancada de três a cinco vezes por semana. [...] Eu desejava que meus pais estivessem mortos (Baer, 2007, p. 16-17).

Poucas são as referências sobre a biografia de Karen, mas sabemos que ela, desde pequena, com seus 6 meses de idade, passava uma vida entre médicos 
e hospitais, por causa de um tumor na testa. 0 tumor era grande e deformava seu rosto. Seus pais não aceitavam e quiseram colocar Karen para adoção. Desde essa época, Karen já era fisicamente abusada.

Quando Karen tinha 11 anos de idade, seu pai realizou uma "festinha" em casa. Cobrou 50 dólares de um de seus funcionários e entregou sua filha para ter relações sexuais com ele. Aos 12 anos, Karen viveu um marcante ritual de abuso. A "casa de funeral" era o local de trabalho de um vizinho e, ao mesmo tempo, local de outra festa realizada por seu pai.

Era madrugada, e Martin, pai de Karen, tira ela da cama, arruma-a, e ambos vão andando até a "casa de funeral". Ao entrarem, Karen é levada para o porão; as vozes e o cheiro de formol são impregnantes. 0 ambiente está iluminado por velas e há latas de cerveja espalhadas pelo local.

Martin encaminha Karen até o centro da sala, tira suas roupas e a deita numa mesa de aço, que serve para abrir e arrumar os corpos para o enterro. "Tire suas calças, Karen [...] nós vamos fazer você se sentir bem" (Baer, 2007, p. 78-79). Karen, nua da cintura para baixo, é deitada na maca e questionada: "Você quer que nós te amemos?". "Você tem um coração e uma alma negros, [...] todos sabem que você é má". Quando Martin saiu de perto da mesa, os outros homens se aproximaram, a tocaram, e a furaram com agulhas em seu abdômen. "Para ser amada, você deve sofrer, [...] Você deveria nos agradecer por amar você".

Sua mãe a maltratava moralmente, seu pai e seu avô, sexualmente. Certa vez, seu pai e seu avô a levaram para tomar sorvete, mas desviaram o caminho e foram até a fábrica onde seu avô trabalhava. Ficou deitada numa mesa, enquanto o avô proferia palavras como num ritual religioso:

aqui está ela, a puta do demônio [...] A palavra de Deus nos uniu! [...] O mundo está uma bagunça [...] Nós dizemos que você deve ser punida, e você deve se punir sempre enquanto estiver na terra. Esta é a palavra de Deus. Se contar a alguém de fora sobre a palavra de Deus, você deve se matar, depois de matar a pessoa para quem contou. Você deve fazer isso, ou o mal estará sempre com você (Baer, 2007, p. 82).

Depois do sermão, Karen sentiu uma presença forçando o caminho dentro dela.

Para Baer, essas histórias não pareciam ter sido geradas por fantasias; uma vez que o grau de sadismo e manipulação era grande demais para serem de autoria da paciente. Porém, sabia que não importava, pois, verdade real ou fantasia, o que devia ser levado em conta para o tratamento era o fato de que Karen viveu essas experiências.

No início do tratamento, quando Karen conta a seu médico essas experiências, lacunas de tempo são flagradas como evidências de que algo mais estava acontecendo dentro da mente de Karen. Ao longo do livro, essas lacunas vão sendo preenchidas com as memórias aprisionadas por cada alterego; cada personalidade possuía um pedaço da história dessas atrocidades, o que levou Baer a concluir que cada alter nascia, ou era formado, com uma função específica.

Ao todo eram 17 personalidades alternantes: Holdon, Jensen, Karen Boo, Sidney, Claire, Miles, Thea, Karl, Elise, Julie, Katherine, Ann, Sandy, Karen 1, Karen 2, Karen 3 e Juliann. Dessas, podemos destacar as funções e características principais de algumas. Holdon era a imagem interna de um pai, assim como Katherine de uma mãe. Pais fantasiados e desejados por Karen, aqueles que cuidavam de todo o sistema das personalidades ("sistema" era como chamavam seu mundo interno). Eram eles que decidiam quando e quem deveria sair; tomavam conta da casa e da vida de Karen. Jensen, o desenhista, era negro. Afirmava que nasceu negro, pois o pai de Karen não gostava de negros. Karen Boo era um bebê, foi uma das primeiras a nascer e levou com ela a dor do tumor, que Karen não podia suportar.

Miles e Karl eram as personalidades que guardavam a maior carga de dor e sofrimento dos abusos realizados. Karen 2 foi a personalidade que se casou e teve o primeiro filho; era ela quem tinha relações sexuais com Josh, o marido de Karen. Karen 3 era a personalidade que permaneceu dormente por quase toda a vida, sendo levada a tomar parte do sistema, novamente, depois do nascimento de Sara. Por isso, desconhecia seu passado.

Como podemos perceber, não existe uma personalidade-base; existe um corpo. Este é tomado por alguma personalidade em um período específico de tempo, para efetuar uma tarefa. Esse, pelo menos, era o discurso do "sistema".

Interessante apontar que todas as personalidades foram integradas em "Karen". Essa, por sua vez, não fora tratada como uma personalidade alternante, nem como uma personalidade-base, mas como Karen.

Em relação ao nascimento das personalidades, é dito o seguinte: 
nós começamos a nos separar quando Karen era apenas um bebê. Os abusos começaram mesmo antes de seu nascimento, durante a gravidez de sua mãe. Eu entendo que seu pai socava sua mãe quando ela estava grávida. Os alters construíram uma vida para ela. A maioria das outras partes nasceu por razões especiais (Baer, 2007, p. 169).

Dessa forma, a hipótese central de Baer em seu livro - hipótese esta apresentada pelo próprio sistema - é que os alters formavam uma defesa do psiquismo. Eram criados para funcionar de maneira que separavam a dor e o sofrimento causados pelos abusos, desconectando-os do aparelho psíquico; assim, Karen poderia continuar vivendo "normalmente".

Nas palavras de Holdon, sobre seu próprio nascimento, encontramos:

eu, Holdon, nasci dentro desta linda criança, Karen, em 8 de fevereiro de 1961. Karen, na época, tinha 20 meses. Eu, na companhia de Katherine, nos juntamos à Karen Boo no que começou a ser nosso muito necessário e complexo sistema de sobrevivência. Karen começava a chorar toda vez que seu pai chegava perto e desesperadamente precisava de uma figura paterna para protegê-la, e, em sua mente, criou-me. Eu me tornei o protetor de todos. Embora Karen acreditasse que eu envelhecia como ela, não era bem assim. Eu nasci com 2 anos de idade, e envelheci rapidamente. Na época que Karen tinha 5, eu tinha 20. [...] Eu envelhecia de acordo com a necessidade e as mudanças em nosso mundo interno. Nunca ouve uma agenda para dizer como ou se precisávamos envelhecer (Baer, 2007, p. 315).

Até certo ponto, o Dr. Richard Baer tratou Karen a partir da teoria psicanalítica. Porém ao se deparar com o sistema complexo que havia em sua mente, começou a aplicar a hipnose; não sem lembrar a si mesmo, durante vários momentos, de, na medida do possível, usar muito pouco da sugestão.

A hipnose proporcionou, nesse caso, a integração, caracterizada pela união das personalidades alternantes com a personalidade escolhida para ser a única a restar depois do tratamento. Funciona da seguinte maneira: em transe hipnótico, o Dr. Baer apresenta à Karen a personalidade a ser integrada, informa-lhe sobre como e porque a referida personalidade nasceu. 0 alter se aproxima de Karen, encosta nela ou senta sobre ela e, "puf", está integrada. Obviamente, as lembranças e sentimentos que o alter continha são, aos poucos, no decorrer dos dias depois da integração, apresentados a Karen.

Todo o processo se passa no mundo interno de Karen, num quarto dentro da casa do sistema construído especialmente para o Dr. Baer, o “Karen's safe room", o quarto seguro da Karen.

Holdon foi o último a se integrar. E acompanhado dele, as lembranças e sentimentos que continha e que protegia de Karen.

Nossa proposta, desde o início deste artigo, é apresentar reflexões sobre a entidade clínica denominada Desordem de Personalidades Múltiplas, e elaborar conjecturas acerca de sua etiologia e mecanismo de funcionamento.

É chegado o momento, pois, de pensarmos, sob o auxílio da teoria psicanalítica, o que ocorre com o sujeito que necessita elaborar um mecanismo tão particular de posicionamento no mundo, como a divisão (splitting) de sua personalidade.

Freud (1940/1996e, p. 215), em 1940, no seu texto "Esboço de Psicanálise", afirma que:

mesmo num estado tão afastado da realidade do mundo externo como o de confusão alucinatória, aprende-se com os pacientes, após seu restabelecimento, que, na ocasião, em algum canto da mente (como o dizem) havia uma pessoa normal escondida, a qual, como um espectador desligado, olhava o tumulto da doença passar por ele.

Podemos provavelmente tomar como verdadeiro, de modo geral, que o que ocorre em todos esses casos é uma divisão (split) psíquica. Duas atitudes psíquicas formaram-se, em vez de uma só - uma delas, a normal, que leva em conta a realidade, e outra que, sob a influência das pulsões, desliga o ego da realidade.

Antes de prosseguir em nossas análises, advertimos o leitor de que não é por termos usado essa citação que entenderemos a DPM como uma confusão alucinatória, muito menos uma psicose; pelo menos, não a princípio.

Tomamos essa citação para exemplificar ao leitor o que Freud pensou a respeito da divisão, que ele nomeia split, do Ego, e como essa divisão pode ser pensada nos casos aqui relatados.

Mas por que não entendemos, a princípio, os casos de Múltiplas Personalidades como uma psicose? Permitam-nos somar a essa citação outra afirmação freudiana, contemplada em "As Neuropsicoses de Defesa", e que nos permite imaginar a divisão (split) do Ego como concernente a todo sujeito. Consoante 
Freud (1894/1996a, p. 53), "pode-se considerar geralmente aceito que a síndrome da histeria, tanto quanto é inteligível até o momento, justifica a suposição de que haja uma divisão da consciência, acompanhada da formação de grupos psíquicos separados".

Se tomarmos a teoria do aparelho psíquico freudiano, completaremos a ideia de que o ser humano é um ser dividido por natureza. Ademais, nas palavras de Thá (2007, p. 28) encontramos que "processos mentais como estes não são privativos dos neuróticos, mas ocorrem com todas as pessoas". Além disso, os processos "que produzem sintomas são os mesmos que produzem sonhos, os atos falhos e os chistes"; o que implica dizer que "em todas as pessoas há processos mentais que ocorrem fora da consciência, ou seja, de maneira inconsciente", caracterizando a universalidade da divisão humana.

Não é, então, prerrogativa da psicose possuir uma divisão psíquica. Com esse entendimento, parece-nos mais interessante acompanhar as reflexões de Freud acerca da histeria, para conjecturarmos nossas próprias reflexões acerca da DPM.

Em “A Etiologia da Histeria”, Freud (1896/1996c, p. 189) nos diz que "o estado histérico é um efeito tardio e duradouro de uma emoção vivida no passado", e que a etiologia da histeria deve ser buscada, e repousa, na vida sexual infantil. Para o autor,

as experiências sexuais infantis que consistem na estimulação dos órgãos genitais, em atos semelhantes ao coito, e assim por diante, devem portanto ser consideradas, em última análise, como os traumas que levam a uma reação histérica nos eventos da puberdade e ao desenvolvimento de sintomas histéricos (Freud, 1896/1996c, p. 203).

Afirma, ainda, que "a eclosão da histeria pode ser quase invariavelmente atribuída a um conflito psíquico que emerge quando uma representação incompatível detona uma defesa por parte do ego e solicita um recalcamento" (Freud, 1896/1996c, p. 203).

Mas o que aconteceu com Sybil ou Karen, que foi elevado a grau de traumático? Teria o abuso sexual, por si só, esse efeito? Freud propõe que os comportamentos infantis que deveriam ser considerados como trauma sejam a "estimulação dos órgãos genitais, em atos semelhantes ao coito, e assim por diante" (Freud, 1896/1996c, p. 203). Dessa maneira, entendemos que o que se torna traumático não necessariamente é um fato recebido pelo sujeito (ou nunca o é?), como o abuso sexual, mas algo que o próprio sujeito realiza (estimulação ativa do sujeito). Dessa maneira, entendemos que, por parte do sujeito, no nosso caso, Karen e Sybil, havia alguma ligação libidinal em relação ao que ocorria; que as colocava, mesmo em alguma instância inconsciente, como responsáveis por um comportamento ativo nesses rituais. E que, por algum motivo, posteriormente, se tornou incompatível com outras representações psíquicas, detonando no Ego uma defesa, e, ulteriormente, a multiplicidade de personalidades.

Além da parte ativa em relação ao trauma, Freud (1894/1996a, p. 57) coloca que a divisão do Ego é, também, ativamente desenvolvida pelo sujeito. Em "As Neuropsicoses de Defesa", Freud diz que,

se a divisão da consciência que ocorre na histeria adquirida se baseia num ato voluntário, temos então uma explicação surpreendentemente simples para o notável fato de a hipnose ampliar regularmente a consciência restrita do histérico e permitir acesso ao grupo psíquico que foi expelido (split off).

Mas o que diferencia a divisão histérica da que ocorre na Desordem de Personalidades Múltiplas? No texto "Sobre o mecanismo psíquico dos fenômenos histéricos: comunicação preliminar", Freud e Breuer (1996, p. 47) afirmam que:

[...] a divisão da consciência, que é tão marcante nos casos clássicos conhecidos sob a forma de 'double conscience', acha-se presente em grau rudimentar em toda histeria, e que a tendência a tal dissociação, e com ela ao surgimento dos estados anormais da consciência que (reuniremos sob a designação de 'hipnoides'), constitui o fenômeno básico dessa neurose.

Consequentemente, entendemos que a sintomatologia apresentada por Karen e Sybil, as múltiplas personalidades, era conhecida de Freud e Breuer sob o nome de double conscience e que, para os autores, ela estava presente em todo caso de histeria, mesmo que em um estado rudimentar. Podemos então classificar a DPM como histeria? Ou devemos pensá-la como outra estrutura psíquica? Não nos cabe solucionar, aqui, tais questões; voltaremos a elas mais adiante. Podemos, todavia, refletir sobre o que faz com que na histeria o splitting seja diferente daquele que ocorre com as pacientes aqui analisadas. Cabem, agora, nossas conjecturas particulares. 
Parece possível pensar que existe algo de quantitativo na diferenciação entre um caso de histeria e um caso de DPM. Pensamos que, por algum motivo que nos escapa à compreensão, nos casos de Sybil e Karen, o que ocorre é uma hipercatexia do grupo psíquico isolado. É como se um grupo de representações fosse separado do Ego por um mecanismo de defesa, mas no inconsciente esse grupo permanecesse enclausurado, como um ser único. Representações que não podem entrar novamente em jogo, senão isoladas dos outros grupos psíquicos; ligadas umas às outras como um ser-cápsula, que não se desmantelou.

Assim, no inconsciente permaneceria um conjunto de representações que vez por outra retornaria, como faz um sintoma; entretanto, de uma maneira particular, a saber, isoladamente, como uma personalidade alternante.

Se o sintoma é classificado por Freud como o retorno do recalcado, o sintoma, na Desordem de Personalidades Múltiplas, é o próprio aparecimento da personalidade alternante.

Em Obsessões e Fobias, Freud (1894-1895/ 1996b, p. 82) mostra que, no sintoma, a representação original (incompatível) pode ser substituída por outra representação, a representação substituta, ou por atos ou impulsos que serviram como medidas de alívio e proteção.

Assim, entendemos que a gênese de uma personalidade alternante é uma medida protetora, que atua no sentido de aliviar a personalidade principal de algo que é incompatível (lembranças e/ou sentimentos) com o conjunto de representações do Ego. Tal personalidade alternante é isolada e parece ficar à disposição do aparelho para, quando necessitar, retomar o posto - e o corpo - e auxiliar o sujeito quando não suportar as vicissitudes da vida. Com isso, o isolamento dos conjuntos de representações no inconsciente parece ser algo diferente do recalcamento neurótico clássico. Não podemos afirmar, todavia, que se trate de uma psicose, uma vez que a divisão não é permeada pela forclusão.

À parte nossas considerações, outras ideias surgem para dar conta do mistério erigido por essa entidade clínica. Essas outras ideias são as críticas ao nosso intuito de legitimar a DPM como uma defesa real e diferente das neuroses clássicas que referimos no início deste artigo.

Com o intuito de favorecer a elaboração acerca da primeira crítica, a saber, o fato de que essa de- sordem é cultural, tendo uma maior prevalência nos Estados Unidos da América, cabe-nos apresentar a definição do quadro clínico ora estudado atualmente aceita pela comunidade científica.

Segundo o DSM-IV-TR da American Psychiatric Association (2002, p. 497), existiria uma classe de transtornos, denominados Transtornos Dissociativos, que seriam classificados como "uma perturbação nas funções habitualmente integradas de consciência, memória, identidade ou percepção do ambiente". Dentro dessa classificação estaria o Transtorno Dissociativo de Identidade, que é "caracterizado pela presença de duas ou mais identidades ou estados de personalidade distintos, que assumem recorrentemente o controle do comportamento do indivíduo, acompanhada por uma incapacidade de recordar importantes informações pessoais e demasiadamente extensa para ser explicada pelo esquecimento normal" (American Psychiatric Association, 2002, p. 497).

Afirma ainda que:

o Transtorno Dissociativo de Identidade reflete um fracasso em integrar vários aspectos da identidade, memória e consciência. Cada estado de personalidade pode ser vivenciado como se possuísse uma história pessoal distinta, autoimagem e identidade próprias, inclusive um nome diferente (American Psychiatric Association, 2002, p. 503-504).

Retomando nossa análise das críticas, o DSM-IV-TR nos propõe o seguinte texto, ao tratar da prevalência do Transtorno Dissociativo de Identidade:

o aumento agudo nos casos relatados de Transtorno Dissociativo de Identidade nos Estados Unidos, nos últimos anos, tem sido objeto de interpretações bastante diversas. Alguns acreditam que uma maior consciência quanto ao diagnóstico entre os profissionais da saúde mental resultou na identificação de casos anteriormente não diagnosticados. Em contrapartida, outros acreditam que a síndrome tem sido excessivamente diagnosticada em indivíduos altamente sugestionáveis (American Psychiatric Association, 2002, p. 505).

Seja por um aumento na capacidade diagnóstica, ou por um aumento na capacidade de sugestionar a patologia, ambas as possibilidades não explicam por que é nos Estados Unidos que a prevalência dos casos relatados é maior. 
De imediato, cabe dizer que essa crítica não parece ter fundamento - o próprio Freud (1912/1996d) relata o caso de Félida X, discutido pelo Dr. Azam, de Bordeaux.

Apoiamo-nos, para explicar nossa posição e sem muito nos estender, nas comunidades espíritas. A Religião Espírita tem como uma de suas doutrinas, a reencarnação; ou seja, há a pressuposição de uma alma que, após a morte do corpo, está livre para futuramente retornar em outro ser. Nesse meio tempo, entre a morte de um corpo e a reencarnação, a alma ficaria livre de seu materialismo e poderia se aproximar de um corpo habitado e se utilizar dele por algum momento. É o que ocorre nos médiuns, pessoas que incorporam espíritos.

Tendo essa manifestação religiosa - e, portanto, social - em vista, que ocorre ao redor do mundo inteiro, não só nos Estados Unidos, lançamos a hipótese de que a encarnação espiritual seria uma manifestação de uma personalidade dissociada.

Dessa maneira, entenderíamos que a Desordem de Personalidades Múltiplas pode ocorrer em qualquer lugar do globo; muito embora o que ocorre nos Estados Unidos possa ser considerado como uma manifestação particular, em forma de "transtorno mental" da entidade clínica.

Corroborando com essa hipótese, há o fato de que os poucos textos sobre o assunto (DPM) remetem a outra manifestação, conhecida como Escrita Automática. Esse fenômeno pode, pensando no Espiritismo, ser relacionado à psicografia, que seria "a capacidade atribuída a certos médiuns de escrever mensagens ditadas supostamente por espíritos" (Psicografia, 2009). No nosso estudo, pode ser considerada uma manifestação dissociada da personalidade do sujeito.

Mas o que pensar sobre a segunda crítica? A questão de que tal manifestação seria apenas uma teatralidade ou, em palavras técnicas da American Psychiatric Association (2002, p. 505), uma "síndrome excessivamente diagnosticada em indivíduos altamente sugestionáveis"?

Quanto à questão da sugestão, nos relatos propostos, não fica evidente nenhum momento sugestivo eficaz na história dos indivíduos, que se possa apontar como gatilho da doença.

Sobre a teatralidade, nos é extremamente difícil opinar. Entretanto, considerar essa entidade clínica como uma teatralidade histérica, é não ter em conta uma possível elaboração de um mecanismo de defesa particular e belamente articulado. Cabe pontuar, também, que, conforme brevemente estudado anteriormente e mais longamente analisado a seguir, não parece possível entender a DPM como uma manifestação neurótica clássica.

No "Projeto para uma psicologia científica", Freud (1950/1996f, p. 403) nos ensina que o recalque trabalha juntamente com o deslocamento (formação de símbolos). Em poucas palavras, o que está recalcado se liga a uma representação (ideia) que possui livre acesso à consciência. Desloca para ela certa quantidade de energia e pode, precariamente, continuar a ter acesso à motilidade; porém, de uma maneira truncada e não original. Nas palavras de Freud, "é como se $A$ [ideia que tem acesso à consciência] tomasse o lugar de $B$ [ideia recalcada]. $A$ tornou-se um substituto, um símbolo de $B$ ", e ainda, " $A$ é acompanhado de consequências que não parecem adequadas, que não se enquadram nele".

Pensando os casos de DPM, é como se o grupo isolado de representações sofresse mais do mecanismo de condensação do que de deslocamento. Não há deslocamento das representações isoladas " $B$ " para " $A$ ". Ou melhor, na verdade, há criação de simbolismos, mas cada personalidade tem sua própria quota. Cada personalidade tem esse mecanismo particularmente desenvolvido. Nos casos estudados, cada alter parece ser um neurótico próprio.

O sujeito como um todo, seu mecanismo de defesa, parece trabalhar com a condensação. As personalidades são condensadas de representações (ideias), que vão constituir um [alter] Ego próprio como que - separado dos outros.

É nesse ponto que pensamos ser possível diferenciar a neurose "clássica" da DPM. Naquela, o retorno do recalcado prioriza o deslocamento (formação de símbolos); nessa, o retorno do isolado, condensado, apresenta-se em bloco único.

Em Freud (1912/1996d, p. 282) encontramos que "os casos descritos como divisão (splitting) da consciência, como o do Dr. Azam, poderiam, de preferência, ser denominados de deslocamento da consciência [...] que oscila entre dois complexos diferentes que se tornam conscientes e inconscientes alternadamente". Mas não confundamos esse "deslocamento da consciência" com o deslocamento da formação de símbolos. Nesse caso, a função da consciência de que fala Freud é, em outras palavras, a atenção. Assim, nesses casos, de DPM, existe o deslocamento da atenção (consciente) entre um complexo (alter) e outro. Esse complexo, ou personalidade alternante, é 
que foi formado pela condensação. É o condensado ao qual nos referimos. É assim que o aglomerado (condensado) de representações toma corpo. É um deslocamento da consciência (atenção) de um condensado para outro. 0 que está atualmente em atenção, está consciente; os outros ficam inconscientes. Entretanto pode-se contrapor à nossa ideia de uma diferenciação em relação à neurose clássica a hipótese de que esse mecanismo particular de condensação aconteça apenas em relação às representações do Ego, que possui uma parte inconsciente. E que o inconsciente recalcado exista igual ao da neurose clássica. Mas, se assim fosse, como os alteregos saberiam tanto da história e da dor dos sujeitos em questão? Novamente, não nos cabe decidir; apenas conjecturar.

Com isso, a princípio, separamos em certa medida a DPM das neuroses, mas tampouco a classificamos como psicose. Ficamos satisfeitos em, nesse momento, conceituá-la como um mecanismo de defesa particular, em uma estrutura psíquica que ainda não sabemos definir. Todavia pudemos delimitar o que, para nós, é o mecanismo de funcionamento e a etiologia da Desordem de Personalidades Múltiplas, uma entidade clínica complexa e mutante.

Mutante no sentido de que pode ser notada em diversas formas na sociedade mundial; seja como double conscience, incorporação espírita, escrita automática, ou "simplesmente" como Transtorno Dissociativo de Identidade.

\section{Referências}

American Psychiatric Association. (2002). Manual diagnóstico e estatístico de transtornos mentais (DSM-IVTR). (Cláudia Dornelles, Trad.). Porto Alegre: Artmed.

Baer, R. (2007). Switching time. New York: Crown.
Breuer, R., \& Freud, S. (1996). Sobre o mecanismo psíquico dos fenômenos histéricos: Comunicação preliminar. Obras psicológicas completas de Sigmund Freud (Vol. II). Rio de Janeiro: Imago. (Originalmente publicado em 1893).

Freud, S. (1996a). As neuropsicoses de defesa. Obras psicológicas completas de Sigmund Freud (Vol. III). Rio de Janeiro: Imago. (Originalmente publicado em 1894).

Freud, S. (1996b). Obsessões e fobias: Seu mecanismo psíquico e sua etiologia. Obras psicológicas completas de Sigmund Freud (Vol. III). Rio de Janeiro: Imago. (Originalmente publicado em 1894-1895).

Freud, S. (1996c). A etiologia da histeria. Obras psicológicas completas de Sigmund Freud (Vol. III). Rio de Janeiro: Imago. (Originalmente publicado em 1896).

Freud, S. (1996d). Uma nota sobre o inconsciente na psicanálise. Obras psicológicas completas de Sigmund Freud (Vol. XII). Rio de Janeiro: Imago. (Originalmente publicado em 1912).

Freud, S. (1996e). Esboço de psicanálise. Obras psicológicas completas de Sigmund Freud (Vol. XXIII). Rio de Janeiro: Imago. (Originalmente publicado em 1940).

Freud, S. (1996f). Projeto para uma psicologia científica. Obras psicológicas completas de Sigmund Freud (Vol. I). Rio de Janeiro: Imago. (Originalmente publicado em 1895; 1950).

Wikipédia: A enciclopédia livre. (2009). Psicografia. Recuperado em 7 jun. 2009, em <http://pt.wikipedia.org/ wiki/Psicografia>.

Schreiber, F. R. (1983). Sybil. São Paulo: Círculo do Livro.

Thá, F. (2007). Categorias conceituais da subjetividade. São Paulo: Annablume. 